\title{
Should the left atrial appendage always be removed in mital valve surgery? in search of a perfect outfit
}

\begin{abstract}
Atrial fibrillation is the most common arrhythmia in worldwide. The left atrial appendage morphology with long body and narrow base, blood stasis and atrial fibrillation increase thrombi formation. Cardioembolic strokes are 17.9-fold more frequent in non-valvular atrial fibrillation patients than those without atrial fibrillation. The efficacy of chronic anticoagulation therapy to prevent ischemic strokes in atrial fibrillation is well established. Adjusted-dose warfarin reduces stroke by $60 \%$ and death by $25 \%$ compared with no antithrombotic treatment. Introduction of NOACs agents has help to increase the proportion of atrial fibrillation patients receiving anticoagulant therapy. However, despite demonstrated efficacy and professional guideline recommendations, oral anticoagulation treatment rates in patients with atrial fibrillation are generally below $60 \%$. Left atrial appendage occlussion has now become the most preferred method of choice for reducing the possibility of stroke in non-valvular atrial fibrillation, especially in cases in which oral anticoagulant therapy is contraindicated. It is well established the usefulness of the left atrial appendage removal in patients with rheumatic mitral valve disease and atrial fibrillation. Theoretically, removal of the left atrial appendage in patients with mitral valve disease in normal sinus rhythm could have several advantages, taking into account that $26 \%$ of mitral valve operations exhibits postoperative atrial fibrillation. Nevertheless, further randomized studies are needed to answer if LAA should be removed in all cases of MV surgery.
\end{abstract}

Volume 8 Issue 2 - 2017

\author{
Ovidio A Garcia Villarreal \\ Department of Cardiovascular Surgery, Hospital Zambrano \\ Hellion, Mexico
}

Correspondence: Ovidio A Garcia-Villarreal, Sierra Nayarita 143, Col,Virginia Tafich, 66374, Santa Catarina, Nuevo León, Mexico, Email ovidiocardiotor@gmail.com

Received:December 12, 2017 | Published: February 16, 2017

\section{Introduction}

It is well know the roll of the left atrial appendage (LAA) as the main thrombi generator in patients with any type of atrial fibrillation (AF). ${ }^{1}$ Cardioembolic strokes are 17.9-fold more frequent in nonvalvular $\mathrm{AF}$ patients than those without $\mathrm{AF}(64.6 \%$ vs $3.6 \%$, p < $0.0001) .{ }^{2}$ According to published data in a 2013 update by Go et al., in USA each year $\approx 795000$ people continue to experience a new or recurrent stroke (ischemic or hemorrhagic), of which one in four are recurrent attacks. In 2009 , stroke caused $\approx 1$ of every 19 deaths in USA. On average, every 40seconds, someone in the United States has a stroke and dies of one approximately every 4 minutes.

Oral anticoagulation (OAC) prevents stroke and improves allcause survival in patients with atrial fibrillation while reducing the risk of thromboembolism by $64 \%$ and all-cause death by $26 \%$ with an acceptable increase in bleeding risk compared with no treatment. ${ }^{4}$ Standardized absolute risk of stroke and for the intracranial bleeding outcome at 1year after initiation of Vitamin $\mathrm{K}$ antagonist has been estimated in $2.01 \%$ and $0.60 \%$, respectively. ${ }^{5}$ On the other hand, taken into account the time with therapeutic range, it has been estimated that the average quality of anticoagulation is $60.5 \%$, and a high percentage of patients have a quality of anticoagulation below recommended levels. ${ }^{6}$ Non-vitamin K antagonist anticoagulants (NOACs) have emerged as another alternative for anticoagulation treatment in patients with non-valvular AF. Introduction of NOACs agents has help to increase the proportion of atrial fibrillation patients receiving anticoagulant therapy. Use of NOACs is rising rapidly and accounts for half of all anticoagulant used during AF. Indeed, rivaroxaban now accounts for half of all NOACs use in AF patients among this population. ${ }^{7}$ However, despite demonstrated efficacy and professional guideline recommendations, $\mathrm{OAC}$ treatment rates in patients with $\mathrm{AF}$ are generally below $60 \%{ }^{8}$

This leads, in turn, to problems that convey a lack of safety in terms of stroke risk. In a series reported by Hess et al., ${ }^{9}$ untreated patients had a higher risk of death (adjusted hazard ratio (HR) 1.22, 95\% CI 1.05-1.41), a lower bleeding risk (adjusted HR 0.35, 95\% CI 0.15-0.81) and a nonsignificant trend toward higher risk of stroke/ non-central nervous system embolism/transient ischemic attack than those treated (adjusted HR 1.18, 95\% CI 0.91-1.54).

Against this background, LAA occlussion has now become the most preferred method of choice for reducing the possibility of stroke in non-valvular AF, especially in cases in which OAC is contraindicated. ${ }^{10}$ In fact, Briceno et al., ${ }^{11}$ have demostrated that NOACs is superior to warfarin for stroke prevention in non-valvular $\mathrm{AF}$, as well as Watchman left atrial appendage occlusion device is a reasonable noninferior alternative to warfarin for stroke prevention.

However, nowadays there is a lack of exact data on the relationship between LAA and stroke in valvular AF. This may partially be explained by the fact that rheumatic disease is almost completely eradicated in the developed countries. Therefore, the most recent articles in the stronger impact factor journals are focused on nonvalvular AF. In underdeveloped or emerging countries having high rates of prevalence for rheumatic heart disease, mitral valve (MV) disease ranks in the third place in cardiac surgery. In Mexico, $48 \%$ of cases undergoing MV surgery have AF. Of these, in rheumatic mitral valve disease long-standing $\mathrm{AF}$ is present in almost $87 \%$ at the time of operation. Unfortunately, maze procedure indications in accordance to the latest $\mathrm{AF}$ guidelines ${ }^{12}$ are not uniformly applied in most of cases. Success rate for Cox-maze procedure in rheumaic MV disease with valvular AF is actually $83 \%$ at 5 years in a mexican series of patients. ${ }^{13}$ Question about whether or not the only removal of the LAA in cases with rheumatic MV disease and valvular AF is enough to reduce the rate of stroke risk has already been partially answered. In fact, usefulness of LAA removal in cases with valvular AF has recently been demostrated. In a series of 23 patients having rheumatic MV disease and AF, the only LAA removal was associated with no stroke after the third postoperative month in a 6months follow-up in 
patients with MV repair or biological prosthesis..$^{14}$ Nonetheless, there is no uniform consensous for cases with MV disease and normal sinus rhythm undergoing cardiac surgery.

Some of the advantages related to the LAA resection in MV surgery could be:

i. To prevent against further cardioembolic events AF-related, taking in mind that up to $24 \%$ of MV operations develop new postopertive AF. ${ }^{15}$

ii. No need for long-term oral anticoagulation therapy in cases with MV repair or biological replacement, even when AF being present in the postoperative period. Alternatively, NOACs may become the only required therapy. ${ }^{16}$

At glance, it would seem that LAA should always be removed in all cases of MV surgery, regardless preoperative cardiac rhythm. By contrast, Malduni et al. ${ }^{17}$ have shown that LAA closure during routine cardiac surgery is significantly associated with an increased risk of early postoperative AF, but does not influence the risk of stroke or mortality. Yet further randomized studies are needed to answer if LAA should be removed in all cases of MV surgery.

\section{Acknowledgments}

None.

\section{Conflicts of interest}

Author declares there is no conflicts opf interest.

\section{Funding}

None.

\section{References}

1. Johnson WD, Ganjoo AK, Stone CD, et al. The left atrial appendage: our most lethal human attachment! Surgical implications. Eur J Cardiothorac Surg. 2000;17(6):718-722.

2. Yamanouchi H, Nagura H, Mizutani T, et al. Embolic brian infarction in nonrheumatic atrial fibrillation: a clinicopathologic study in the elderly. Neurology. 1997;48(6):1593-1597.

3. Go AS, Mozaffarian D, Roger VL, et al. American Heart Association Statistics Committee and Stroke Statistics Subcommittee. Executive summary: heart disease and stroke statistics--2013 update: a report from the American Heart Association. Circulation. 2013;127(1):143-152.
4. Hart RG, Pearce LA, Aguilar MI. Meta-analysis: antithrombotic therapy to prevent stroke in patients who have nonvalvular atrial fibrillation. Ann Intern Med. 2007;146(12):857-867.

5. Staerk L, Fosbøl EL, Lip GY, et al. Ischaemic and haemorrhagic stroke associated with non-vitamin $\mathrm{K}$ antagonist oral anticoagulants and warfarin use in patients with atrial fibrillation: a nationwide cohort study. Eur Heart J ehw. 2016;496.

6. Rivera-Caravaca JM, Viedma-Viedma I, Roldán V. Factors affecting the quality of anticoagulation with vitamin $\mathrm{K}$ antagonists in venous thromboembolism Patients. Biol Res Nurs. 2016;19(2):198-205.

7. Barnes GD, Lucas E, Alexander GC, et al. National trends in ambulatory oral anticoagulant use. Am J Med. 2015;128(12):1300-1305.e2.

8. Kirley K, Qato DM, Kornfield R, et al. National trends in oral anticoagulant use in the United States, 2007 to 2011. Circ Cardiovasc Qual Outcomes. 2012;5(5):615-621.

9. Hess PL, Kim S, Fonarow GC, et al. Absence of oral anticoagulation and subsequent outcomes among outpatients with atrial fibrillation. $\mathrm{Am}$ J Med pii. 2016;S0002-9343(16)31195-0.

10. Sakellaridis T, Argiriou M, Charitos C, et al. Left atrial appendage exclusion-Where do we stand? J Thorac Dis. 2014;6(S1):S70-S77.

11. Briceno DF, Villablanca P, Cyrille N, et al. Left Atrial Appendage Occlusion Device and Novel Oral Anticoagulants Versus Warfarin for Stroke Prevention in Nonvalvular Atrial Fibrillation: Systematic Review and Meta-Analysis of Randomized Controlled Trials. Circ Arrhythm Electrophysiol. 2015;8(5):1057-1064.

12. Kirchhof P, Benussi S, Kotecha D, et al. 2016 ESC Guidelines for the management of atrial fibrillation developed in collaboration with EACTS. Eur J Cardiothorac Surg. 2016;18(11):1609-1678.

13. García-Villarreal OA. Cox-maze III procedure for atrial fibrillation. A preliminary study. Arch Cardiol Mex. 2016;86(3):208-213.

14. García-Villarreal OA, Heredia-Delgado JA. Left atrial appendage in rheumatic mitral valve disease: The main source of emboli in atrial fibrillation. Arch Cardiol Mex pii. 2016;S1405-9940(16)30112-4.

15. Kernis SJ, Nkomo VT, Messika-Zeitoun D, et al. Atrial fibrillation after surgical correction of mitral regurgitation in sinus rhythm. Incidence, outcome, and determinants. Circulation . 2004;110(16):2320-2325.

16. García-Villarreal OA. Bioprosthetic heart valves: Can they be anticoagulated with NOACs? J Cardiol Curr Res. 2016;7(1):00239.

17. Melduni RM, Schaff HV, Lee H-C, Gersh BJ, et al. Impact of left atrial appendage closure during cardiac surgery on the occurrence of early postoperative atrial fibrillation, stroke, and mortality: A propensity score matched analysis of 10,633 patients. Circulation. 2016;135(7). 